\title{
Annelerin doğum sonu dönemde ebeveynlik davranışlarının değerlendirilmesi*
}

\author{
Hava Özkan ${ }^{1}$, Ayla Kanbur ${ }^{1}$, Serap Apay ${ }^{1}$, Meral Kılıç${ }^{1}$, Safiye Ağapınar ${ }^{1}$, Elif Yağmur Özorhan ${ }^{1}$
}

ÖZET:

Annelerin doğum sonu dönemde ebeveynlik davranışlarının değerlendirilmesi

Amaç: Doğumdan sonraki ilk karşılaşmada anne veya babanın, bebeğe karşı gösterdiği davranışlar ilk ebeveynlik davranışı olarak kabul edilmektedir. Araştırma, annelerin doğum sonu dönemde ebeveynlik davranışIarının değerlendirilmesi amacıyla yapılmıştır.

Yöntem: Tanımlayıcı nitelikte olan araştırma; Kadın-Doğum Hastanesinde Ocak 2011-Mayıs 2011 tarihleri arasında vajinal doğum yapan, sağlıklı bebeğe sahip olan 234 anne ile tamamlanmıștır. Veriler; anket formu ve Britton ve arkadaşları (2001) tarafından geliştirilen, Çalışır ve arkadaşları (2009) tarafından geçerliliği yapıImıs "Doğum Sonrası Ebeveynlik Davranışı Ölçeği" (DSEDÖ) ile toplanmıștır. Doğumdan sonra anne ve bebeğin karşılaştığı ilk 10 dakika süresince gözlemci, annenin bebeğine karşı gösterdiği davranışları gözlemleyerek, var olan davranışa (+), olmayan davranışa (-) işareti koyarak kaydetmiştir. Altı maddeli ölçeğin, her bir maddesi için davranıs gözlenmişse bir (1) puan, gözlenmemişse sıfır (0) puan olarak değerlendirilir. Ölçekten alınan toplam puanın yüksek olması ebeveynin bebeğine karşı olumlu ebeveynlik davranışına sahip olduğunu göstermektedir. Annenin doğal davranışını gözleyebilmek için önce DSEDÖ, sonra anket formu gözlemci tarafından doldurulmuştur. Her anket formu ve DSEDÖ için yaklaşık 15 dakikalık süre kullanılmıştır. Araştırmaya başlamadan önce etik kurul kararı ve kurumdan izin alınmıştır. Doğuma gelen gebelere açıklama yapılarak ve doğumdan sonra gözlemin herhangi bir zamanda yapılacağı bildirilerek katılmak isteyenlerin onamları alınmıştır. Verilerin değerlendirilmesinde; yüzdelik dağıım, varyans analizi ve t testi kullanılmıştır. Bulgular: Annelerin \%66.7'sinin 20-29 yas grubunda olduğu, \%77.8'inin isteyerek gebe kaldığı belirlenmiştir. Annelerin \%9'u "0" puan alırken, \%17.5'i "6" puan almışlardır. Annelerin toplam puan ortalaması $3.20 \pm 1.95$ olarak bulunmuştur.

Annelerin; aile tipine, eğitim durumlarına, eşlerin eğitim durumlarına ve gelir düzeylerine göre ( $p<0.001)$, gebeliği isteme durumlarına göre DSEDÖ puan ortalamaları arasında anlamlı bir ilişki bulunduğu belirlenmiştir $(p<0.05)$

Sonuçlar: Annelerin, ebeveynlik davranışı puan ortalamalarının orta düzeyde olduğu, aile tipi, eğitim, gelir düzeyleri ve gebeliğin istenmesinin puan ortalamalarını etkilediği saptanmıştır.

Anahtar kelimeler: Anne, doğum sonu, ebeveynlik davranışı

\section{ABSTRACT:}

The evaluation of parenthood attitudes of the mothers in postpartum period

Aim: In the first meeting after labor, attitudes of mother and father towards the infant are accepted as the first parenthood attitudes. This study was carried out with the aim of evaluating parenthood attitudes of mothers in post-partum period.

Method: The study, descriptive one, was carried on 234 mothers having healthy babies and giving vaginal birth at Women Labor Hospital between the dates Jan 2011 and May 2011. The data were collected by means of survey form and The Scale of Parenthood Attitude After Labor (SPAAL) validated by Çalışır et al (2009) and developed by Brittion et al (2001). During the first ten minutes when mother and father met after the labor, the observer followed the attitude of the mother towards her baby, and recorded as $(+)$ for existing attitude, as (-) for unavailable attitude. In the scale consisting of six articles, if an attitude is observed for each article, it is given one point (1), if it isn't observed, it is evaluated as (0) point. The fact that total score taken from the scale become high indicates that parents had positive parenthood attitude towars their infant. In order to observe natural attitude of mother, firstly, the Scale of Parenthood Attitude After Labor was filled, and then survey form was filled by observer. About 15 minutes were used for both survey forms. Before starting to the study, the decision of ethic board and permission of organization were taken. Explanations fort he pregnants coming for the labor were made, and was reported that observations after labor would be made at any time, and approval was taken from those who won't to participate in. In the evaluation of the data, variance analysis and t-test were used.

Findings: It was determined that $66.7 \%$ of the mothers were in $20-29$ age group, and that $77.8 \%$ of the mothers became pregnant villingly. While $9 \%$ of mother took "0" poin, $17.5 \%$ took "six" (6) point. It was found out that total score average of the mothers was $3.20 \pm 1.95$.

It was also determined that, according to type of life, education level, educational level of the spouses ( $p<0.001$ ), and villingness about pregnancy, there was a significant relationship between score averages of The Scale of Parenthood Attitude After Labor ( $p<0.05)$.

Results: It was found out that score averages of parenthood attitude of mothers were in moderate level, and that type of family, education, revenue levels and villingness about pregnancy affected score averages. Key words: Mother, after labor, parenthood attitude

Ş.E.E.A.H. Tıp Bülteni 2013;47(3):117-121
*Bu araştırma, Uluslararası Katıımlı 3. Ulusal Pediatri Hemşireliği Kongresi 6-9 Eylül 2011 tarihinde Izmir'de Poster Bildiri olarak sunulmuştur.

'Atatürk Üniversitesi Sağlık Bilimleri Fakültesi, Erzurum-Türkiye

Yazışma Adresi / Address reprint requests to: Hava Özkan,

Atatürk Üniversitesi Sağlık Bilimleri Fakültesi, Erzurum-Türkiye

Telefon / Phone: +90-532-330-0036

E-posta / E-mail:

havaorhan67@hotmail.com

Geliş tarihi / Date of receipt: 18 Mart 2013 / March 18, 2013

Kabul tarihi / Date of acceptance: 11 Eylül 2013 / September 11, 2013 


\section{GíRiş}

Annelik; kadına bebeğinin yaşamının önemli bir parçası olduğunu hissettiren ve duygusal enerji sağlayan bir anlam taşır. Bu duygusal enerji, annenin bebeğine karşı ılımlı, bağlı, koruyucu olmasını ve ilgi göstermesini sağlamaktadır (1).

Doğumdan önce, bebeğini tanımaya ve algılamaya başlayan anne, bebek doğduktan sonra bebeğini keşfetmeye çalışır (2). Bebeğin yüzünü, ellerini ve vücudunun diğer bölümlerini inceler, bebekle göz teması kurmaya çalışır ve onunla konuşur (3). İnsan yaşamındaki en önemli kararlardan biri olan ebeveyn olma gebeliğe karar verme ile başlayan ve yaşam boyu devam eden bir süreçtir (4). Anne-bebek arasındaki bağlanmanın en önemli bölümü doğumdan önce başlar ve doğumdan sonraki aylarda gelişerek devam eder. Doğumdan sonraki erken dönem, bağlanmanın en yoğun yaşandı̆̆ı dönem olması nedeniyle olumlu anne-bebek ilişkisinin başlatılması için uygun zamandır (2,4-7). Doğumdan sonraki ilk karşılaşmada, anne veya babanın bebeğe karşı gösterdiği davranışlar ilk ebeveynlik davranışı olarak kabul edilmektedir $(2,3)$. Ebeveynin gösterdiği bu davranışlar; bebeğin el ve ayaklarına dokunma, okşama, bebekle konuşma, göz temasında bulunma, bebeği inceleme gibi davranışlardır (8). Doğumdan sonraki ilk karşılaşmada annenin bebeğine karşı gösterdiği davranışlar ilerleyen dönemde anne-bebek arasındaki bağlanma süreci hakkında önemli ipuçları vermektedir. Lohusa ve bebek bakımından sorumlu olan ebe ve hemşirelerin, anne-bebek arasında doyurucu ve zevk verici bir etkileşimin oluşması, sevgi bağının güçlenmesi ve gelişimin değerlendirilmesi için annenin ebeveynlik davranışlarının dikkatle gözlemesi önemlidir (6-10).

$\mathrm{Bu}$ araştırma; annelerin doğum sonu dönemde ebeveynlik davranışlarının değerlendirilmesi amacıyla yapılmıştır.

\section{GEREÇ VE YÖNTEM}

Araştırma, Erzurum il merkezinde bulunan KadınDoğum Hastanesinde Ocak 2011-Mayıs 2011 tarihleri arasında 234 kişi ile tanımlayıcı tipte yapılmıştır. Araştırmanın evrenini belirtilen tarihler arasında Kadın Doğum Hastanesinde doğum yapan anneler, örneklemini ise; evrenden olasılıksız rastlantısal örnekleme yöntemi ile seçilen araştırmaya gönüllü katılmayı kabul eden ve anne ve bebek sağlığı açısından herhangi bir risk taşımayan anneler oluşturdu.

Araştırma verileri, anket formu ve Doğum Sonrası Ebeveynlik Davranışı Ölçeği (DSEDÖ) ile toplanmıştır. Anket formu, annelerin demografik özelliklerini ve obstetrik öykülerini belirlemek üzere araştırmacılar tarafından hazırlanmış 12 sorudan oluşmaktadır.

Araştırmanın bağımsız değişkenleri; annelerin demografik özellikleri ve obstetrik öyküleri, bağımlı değişkeni ise; Doğum Sonrası Ebeveynlik Davranışı Ölçeğinden alınan puan ortalamalarından oluşmaktadır.

Doğum sonrası erken dönemde ebeveynlik davranışını belirlemek üzere Britton ve ark. (2001) tarafından geliştirilen ölçeğin (11), Türkçe geçerlik ve güvenirliği Çalışır ve ark. (2009) tarafından yapılmıştır (8). Ölçeğin uygulamasında, doğumdan sonra ebeveyn ve bebeğin karşılaştığı ilk 10 dakika süresince gözlemci, ebeveynin bebeğine karşı gösterdiği davranışları gözlemleyerek, var olan davranışa artı (+) ve olmayan davranışa eksi (-) işareti koyarak kaydeder. Her bir madde, davranış gözlenmişse bir (1) puan, gözlenmemişse sıfır (0) puan olarak değerlendirilir. Toplam ölçek puanı her maddeden elde edilen sayıların toplamından oluşur. Ölçeğin toplam puanı 0-6 puan arasındadır. Ölçekten alınan toplam puanın yüksek olması ebeveynin bebeğine karşı daha olumlu ebeveynlik davranışına sahip olduğunu göstermektedir (8).

Postpartum odasına alınan annelerin bebeklerini emzirmeleri sağlandıktan sonra veriler toplanmaya başlanmıştır. Annenin doğal davranışını gözleyebilmek için önce DSEDÖ, sonra anket formu gözlemci tarafından doldurulmuştur. Ölçeğin uygulamasında, doğumdan sonra ebeveyn ve bebeğin karşılaştığı ilk 10 dakika süresince gözlemci, annenin bebeğine karşı gösterdiği davranışları gözlemlemiş, var olan davranışa artı (+) var olmayan davranışa eksi (-) işareti koymuştur. Her anket formu ve DSEDÖ için yaklaşık 15 dakikalık süre kullanılmıştır. Araştırmaya başlamadan önce etik kurul kararı ve ilgili kurumdan izin alınmıştır. Doğuma gelen gebelere araştırma hakkında açıklama yapılarak, doğumdan sonra gözlemin herhangi bir zamanda yapılacağı bildirilerek katılmak isteyenlerin rızaları alınmıştır. 
Çalışır'ın araştırmasında Cronbach Alpha güvenirlik katsayısı 0.85-0.93 arasında olduğu, yaptığımız araştırmada ise Cronbach Alpha güvenirlik katsayısı 0.86 olarak bulunmuştur. Verilerinin değerlendirilmesinde yüzdelik dağılım, varyans analizi ve t testi kullanılmıştır.

\section{BULGULAR}

Annelerin; \%66.7'si 20-29 yaş grubunda, \%50.4'ünün çekirdek ailede yaşadığı, \%75.7'sinin ilkokul mezunu olduğu, \%94.4'ünün çalışmadığı, \%53'üçünün gelirlerinin gidere denk olduğunu ifade ettikleri, \%32.9'unun ilk gebelikleri olduğu, \%30.3'ünün ilk çocuklarının olduğu, \%77.8'inin isteyerek gebe kaldığı, \%63.2'sinin dört yıl ve üzerinde evli oldukları ve \%50.9'unun bebeklerinin cinsiyetinin erkek olduğu belirlenmiştir (Tablo 1).

Araştırmada, annelerin tanıtıcı özellikleri ve obstetrik öykülerine göre DSEDÖ puan ortalamaları incelendiğinde; 30 yaş üstü annelerin $3.31 \pm 1.95$, üniversite mezunu annelerin $4.90 \pm 1.30$, çalışan annelerin

Tablo 1: Annelerin tanıtıcı özelliklerinin DSEDÖ puan ortalamaları ile karşılaştırııması

\begin{tabular}{|c|c|c|c|c|}
\hline Özellikler ( $n=234)$ & Sayı & $\%$ & DSEDÖ $\pm S S$ & Test ve Önemlilik \\
\hline \multicolumn{5}{|l|}{ Yaş Grubu } \\
\hline $15-19$ & 18 & 7.7 & $2.88 \pm 2.13$ & $f=0.33$ \\
\hline $20-29$ & 156 & 66.7 & $3.20 \pm 1.94$ & $\mathrm{df}=2$ \\
\hline 30 yaş ve üstü & 60 & 25.6 & $3.31 \pm 1.95$ & $p>0.05$ \\
\hline \multicolumn{5}{|l|}{ Annenin Eğitim Durumu } \\
\hline ilkokul & 177 & 75.7 & $2.93 \pm 1.91$ & $f=6.27$ \\
\hline Ortaokul & 27 & 11.5 & $4.03 \pm 1.91$ & $\mathrm{df}=3$ \\
\hline Lise & 19 & 8.1 & $3.63 \pm 1.86$ & $p<0.001$ \\
\hline Üniversite & 11 & 4.7 & $4.90 \pm 1.30$ & \\
\hline \multicolumn{5}{|l|}{ Aile Tipi } \\
\hline Çekirdek Aile & 118 & 50.4 & $3.62 \pm 1.98$ & $t=3.37$ \\
\hline Geniş Aile & 116 & 49.6 & $2.78 \pm 1.83$ & $\begin{array}{l}d f=232 \\
p<0.05\end{array}$ \\
\hline \multicolumn{5}{|l|}{ Çalışma Durumu } \\
\hline Çalışan & 13 & 5.6 & $4.00 \pm 1.63$ & $t=1.50$ \\
\hline Çalışmayan & 221 & 94.4 & $3.16 \pm 1.96$ & $\begin{array}{l}d f=232 \\
p>0.05\end{array}$ \\
\hline \multicolumn{5}{|l|}{ Eşin Eğitim Durumu } \\
\hline ilkokul & 111 & 47.4 & $2.75 \pm 1.89$ & $f=6.84$ \\
\hline Ortaokul & 42 & 17.9 & $2.97 \pm 2.03$ & $d f=3$ \\
\hline Lise & 62 & 26.6 & $3.83 \pm 1.74$ & $p<0.001$ \\
\hline Üniversite & 19 & 8.1 & $4.31 \pm 1.91$ & \\
\hline \multicolumn{5}{|l|}{ Gelir Düzeyi } \\
\hline Gelir giderden az & 94 & 40.2 & $2.41 \pm 1.76$ & $f=15.70$ \\
\hline Gelir gidere denk & 124 & 53.0 & $3.66 \pm 1.88$ & $\mathrm{df}=2$ \\
\hline Gelir giderden fazla & 16 & 6.8 & $4.37 \pm 1.92$ & $p<0.001$ \\
\hline \multicolumn{5}{|l|}{ Gebelik Sayısı } \\
\hline 1 & 77 & 32.9 & $3.33 \pm 2.01$ & $f=0.72$ \\
\hline 2 & 58 & 24.8 & $3.13 \pm 1.95$ & $d f=3$ \\
\hline 3 & 49 & 20.9 & $3.40 \pm 1.71$ & $p>0.05$ \\
\hline 4 ve üstü & 50 & 21.4 & $2.90 \pm 2.08$ & \\
\hline \multicolumn{5}{|l|}{ Yaşayan Çocuk Sayısı } \\
\hline Yok & 19 & 8.2 & $2.84 \pm 1.89$ & $f=0.54$ \\
\hline 1 & 71 & 30.3 & $3.39 \pm 1.98$ & $d f=3$ \\
\hline 2 & 73 & 31.2 & $3.08 \pm 1.93$ & $p>0.05$ \\
\hline 3 ve üstü & 71 & 30.3 & $3.25 \pm 1.96$ & \\
\hline \multicolumn{5}{|c|}{ Gebeliğin İstenme Durumu } \\
\hline İsteyen & 182 & 77.8 & $3.42 \pm 1.90$ & $t=3.27$ \\
\hline İstemeyen & 52 & 22.2 & $2.44 \pm 1.95$ & $d f=232$ \\
\hline & & & & $p<0.05$ \\
\hline \multicolumn{5}{|l|}{ Evlilik Yılı } \\
\hline $0-3$ yıl & 86 & 36.8 & $3.12 \pm 2.03$ & $t=0.48$ \\
\hline 4 yıl ve üstü & 148 & 63.2 & $3.25 \pm 1.95$ & $\mathrm{df}=232$ \\
\hline \multirow{2}{*}{\multicolumn{5}{|c|}{ Bebeğin Cinsiyeti }} \\
\hline & & & & \\
\hline $\mathrm{K} I \mathrm{Z}$ & 115 & 49.1 & $3.45 \pm 1.88$ & $t=1.87$ \\
\hline \multirow[t]{2}{*}{ Erkek } & 119 & 50.9 & $2.97 \pm 1.99$ & $d f=232$ \\
\hline & & & & $p>0.05$ \\
\hline
\end{tabular}


Tablo 2: Annelerin DSEDÖ aldıkları puanların dağılımı

\begin{tabular}{lcc}
\hline Puanlar & Sayı & \% \\
\hline 0 & 21 & 9.0 \\
1 & 35 & 15.0 \\
2 & 36 & 15.4 \\
3 & 41 & 17.5 \\
4 & 25 & 10.6 \\
5 & 35 & 15.0 \\
6 & 41 & 17.5 \\
Toplam & 234 & 100.0
\end{tabular}

$4.00 \pm 1.63$, çekirdek ailede yaşayan annelerin $3.62 \pm 1.98$, geliri giderden fazla olan annelerin $4.37 \pm 1.92$, gebelik sayısı 3 olan annelerin $3.40 \pm 1.71$, yaşayan çocuk sayısı 1 olan annelerin $3.39 \pm 1.98$, isteyerek gebe kalanların 3.42 \pm 1.90 , evlilik yılı 4 ve üzerinde olan annelerin $3.25 \pm 1.95$ ve kız bebeği olan annelerin $3.45 \pm 1.88$ olduğu saptanmıştır (Tablo 1).

Yaş grupları, çalışma durumları, gebelik sayısı, yaşayan çocuk sayısı, evlilik yılı ve doğmuş bebeğin cinsiyetine göre annelerin aldıkları DSEDÖ puan ortalamaları değerlendirildiğinde anlamlı bir ilişkinin olmadığı saptanmıştır ( $p>0.05$, Tablo 1$)$.

Annelerin; eğitim durumlarına, eşlerin eğitim durumlarına ve gelir düzeylerine göre DSEDÖ puan ortalamaları değerlendirildiğinde anlamlı bir ilişki bulunduğu $(p<0.001$, Tablo 1$)$, gebeliği isteme ve aile tipine durumlarına göre DSEDÖ puan ortalamaları incelendiğinde anlamlı bir ilişki bulunduğu belirlenmiştir ( $p<0.05$, Tablo 1$)$.

Annelerin \% $\% 9^{\prime} \mathrm{u}$ "0" puan alırken, \%17.5'i "3"puan \%17.5'i "6" puan almışlardır. Annelerin DSEDÖ toplam puan ortalaması $3.20 \pm 1.95$ olarak bulunmuştur.

\section{TARTIŞMA}

İnsan yaşamındaki en önemli kararlardan biri olan ebeveyn olma; eşlerin gebeliğe karar vermeleri ile başlayan ve yaşam boyu devam eden bir süreçtir. Ebeveyn olma ve bir bebeğe sahip olma, anne için mutluluk verici bir olay olmasının yanında yeni rol ve sorumluluk gerektiren bir değişim olması nedeniyle zor bir dönemdir $(4,7,12,13)$. Bu dönemde ebeveynlik davranışının erken dönemde tanımlanması gerekli desteğin verilmesine katkı sağlayabilir (8).

Annelerin eğitim durumlarına göre DSEDÖ puan ortalamaları arasında anlamlı bir ilişki bulunmuştur. Annelerin ebeveynlik davranışının değerlendirildiği araştırmada, üniversite mezunu annelerin DSEDÖ puan ortalamaları diğer eğitim derecelerine sahip olan annelerden yüksek bulunmuştur. Grace'in yaptığı çalışmada doğumdan sonra annelerin, anne olarak kendilerini değerlendirme puanları arasındaki farkı değerlendirdiğinde; lise mezunu anneler ile üniversite mezunu anneler arasında anlamlı fark olduğunu belirtmiştir (14). Grace'in sonuçları, bu araştırma bulguları ile benzerlik göstermektedir.

Annelerin aile tipine göre DSEDÖ puan ortalamaları arasında anlamlı bir ilişki olduğu belirlenmiştir. Çekirdek ailede yaşayan annelerin ebeveynlik davranışı puan ortalamalarının geniş ailede yaşayanlara göre yüksek olduğu bulunmuştur. Özkan'ın yaptığı yarı deneysel çalışmada; çekirdek aile tipine sahip olan deney ve kontrol grubu annelerin annelik puan ortalamalarının geniş aile tipine sahip olan annelere göre yüksek olduğu belirlenmiş ancak istatistiksel olarak anlamlı bir fark olmadığı belirtilmiştir (15). Çekirdek aile tipine sahip annelerin ebeveynlik davranışı puan ortalamalarının yüksek olmasında annelerin bağımsız karar vermelerinin etkili olduğu söylenebilir.

Annelerin eşlerinin eğitim durumlarına göre DSEDÖ puan ortalamaları arasındaki anlamlı ilişki incelendiğinde; üniversite mezunu eşlerin DSEDÖ puan ortalamalarının yüksek olduğu saptanmıştır. Eşin eğitim durumunun yüksek olması annenin bebeği ile olan ilişkisine destek sağlayabilir. Babalık rolüne bilinçli bir şekilde hazır olması puan ortalamalarını etkilemiş olabilir.

Gelir düzeyine göre annelerin DSEDÖ puan ortalamaları arasındaki anlamlı ilişki değerlendirildiğinde; geliri yüksek olan ailelerde yaşayan annelerin ebeveynlik davranışı puan ortalamalarının yüksek olduğu belirlenmiştir. Annelerin ebeveynlik davranışı geliştirirken ekonomik sıkıntı yaşamamaları anne bebek ilişkisinin daha iyi gelişmesini sağlayabilir. Özkan ve Çalışır’ın yaptığı farklı çalışmalarda geliri yüksek olan annelerin puan ortalamalarının yüksek olduğu belirtilmiştir $(15,16)$. Balcı ve Savaşer yaptıkları çalışmada anne-yenidoğan ilişkisinin gelişmesinde ailenin sosyo ekonomik durumu etkili olduğunu belirtmişlerdir (17).

Annelerin gebeliğini isteme durumlarına göre 
DSEDÖ puan ortalamaları arasında anlamlı bir ilişki olduğu belirlenmiştir. İsteyerek gebe kalan annelerin puan ortalamalarının yüksek olduğu bulunmuştur. Gebeliğini planlayan annelerin kendilerini anneliğe hazır hissetmeleri ebeveynlik davranışı puan etkili olmuş olabilir. Gager ve arkadaşları, anne olmayı planlayan bireylerin kendi sorumluluklarına hazırlandıkları ve çocuk bakımı için uygun kaynakları kullanarak başarıya ulaştıkları belirtilmektedir (18).

\section{SONUÇ VE ÖNERILER}

Annelerin, ebeveynlik davranışı puan ortalamalarının orta düzeyde olduğu, aile tipi, eğitim, gelir düzeyleri ve gebeliğin istenmesinin puan ortalamalarını etkilediği saptanmıştır.

Bu sonuçlara göre; kadın doğum kliniklerinde anne adaylarına, başarılı annelik davranışları geliş̧irmelerini sağlamak amacı ile doğum öncesi ve doğum sonrası dönemde, ebeveynlik rollerine geçiş konusunda eğitimlerin verilmesi, konu ile ilgili kitapçık, broşür vb materyalin sağlanması ve bu uygulamaların rutin hale getirilmesi.

Doğum sonu erken dönemde anne-bebek etkileşimini sağlamak için emzirmeye erken dönemde başlayarak, annelerin bebeklerini algılama sürecinin desteklenmesi ve annelerin özgüveninin artırılması önerilebilir.

\section{KAYNAKLAR}

1. Foster $R$, Hunsberger $M$, Anderson J. Family centered nursing care of children. London: W.B. Saunders Company, 1990.

2. Novak J, Broom B. Maternal and child health nursing. 9st edition, Baltimore: Mosby Comp. Publ, St Louis, 1999.

3. Klaus $\mathrm{MH}$, Kennel $\mathrm{JH}$. Care of mother, father, and infant. In: Avroy A. Fanaroff, Richard J. Martin (eds) Neonatal-Perinatal Medicine Diseases of The Fetus and Infant. 6st edition, Mosby Comp. Publ., St. Louis, Baltimore, 1997.

4. Özkan H, Polat S. Annelik davranışını öğrenme süreci ve hemşirelik desteği. Bozok Tıp Dergisi 2011;1(3):35-9.

5. Can G. Anne-yenidoğan bağının önemi. Aysel Ekşi (Editor). Ben Hasta Değilim. Nobel Tıp Kitapevleri Ltd Şt. İstanbul, 1999.

6. Burroughs A, Leifer G. Maternity nursing: an introductory text. 8th edition, London: WB Saunders Company, 2001.

7. Taşkın L. Doğum ve Kadın Sağlığı Hemşireliği. 10. Baskı, Ankara: Sistem Ofset Matbaacılık, 2011.

8. Çalışır H, Karacam Z, Akgül AF, Kurnaz DA. Doğum sonrası ebeveynlik davranışı ölceği'nin Türkce formunun geçerlik ve güvenirliği. Atatürk Üniversitesi Hemşirelik Yüksekokulu Dergisi 2009;12(1):1-8.

9. Işler A. Prematüre bebeklerde anne-bebek ilişkisinin başlatılmasında yenidoğan hemşirelerinin rolü. Perinatoloji Dergisi 2007;15(1):1-6.

10. işler A, Gorak G. Prematüre bebeği olan annelerde olumlu annebebek ilişkisinin başlatılmasında hemşirelik yaklaşımının önemi. Çocuk Dergisi 2007;7(1):36-41.

11. Britton HL, Gronwaldt V, Britton JR. Maternal postpartum behaviors and mother-infant relationship during the first year of life. J Pediatr 2001;138(6):905-9.

12. Özkan H, Polat S. Maternal identity development education on maternity role attainment and my baby perception of primiparas. Asian Nursing Research 2011;(5)2:108-7.

13. Beydağ KD. Doğum sonu dönemde anneliğe uyum ve hemşirenin rolü. TSK Koruyucu Hekimlik Bülteni 2007;6(6):479-84.

14. Grace JT. Mothers' self reports of parenthood across the first 6 months postpartum. Research in Nursing and Health 1993;16(6): 431-9.

15. Özkan H. Annelik kimlik gelişimi eğitiminin primiparların annelik rolü kazanımına ve bebeğim algısına etkisi. Yayınlanmış Doktora Tezi, Atatürk Üniversitesi Sağlık Bilimleri Enstitüsü, Çocuk Sağlığı ve Hastalıkları Hemşireliği AD, Erzurum: 2010.

16. Çalışır H. illk kez Anne Olan Kadınların Annelik Rolü Başarımlarını Etkileyen Etmenlerin Incelenmesi. Yayınlanmamış Doktora Tezi, Ege Üniversitesi, Sağıı Bilimleri Enstitüsü, Çocuk Sağlığı ve Hastalıkları AD, izmir: 2003.

17. BalCı S, Savaşer S. Annelerin bebeklerini algılama durumu. Uluslararasi Katılımlı VI. Ulusal Hemşirelik Kongresi Kitabı, 14-16 Mayıs 1998, Ankara: 1998;215-221.

18. Gager CT, McLanahan SS, Glei DA. Preparing for parenthood: Who's Ready, Who is not? Center for Research on child Wellbeing Working Paper 1998;1-42. 